\title{
Director of Cancer Research Center
}

National Cancer Institute

\section{Source}

National Cancer Institute. Director of Cancer Research Center. NCI Thesaurus. Code C39377.

The Director of Cancer Research Center is professional, administrative, research and academic position with Cancer Center. The incumbent is responsible for the overall direction in the conduct of cancer and allied research; provision and coordination of training in cancer-related research and education; operations, staffing, and maintenance of research facilities; development of new research activities; developing and maintaining relationships with other cancer centers in the nation as well as with international scientific community.' 